\title{
Multipurpose Cooperative Member Participation in Agricultural Input Marketing and Its Associated Factors: Kersa District, Jimma Zone, Oromia Region, Ethiopia
}

\author{
Rusha Begna Wakweya \\ Department of Socioeconomics, Extension, Policy, and Gender, Jimma Environment and Forest Research Centre, Jimma, Ethiopia \\ Email address: \\ rushabegna@gmail.com \\ To cite this article: \\ Rusha Begna Wakweya. Multipurpose Cooperative Member Participation in Agricultural Input Marketing and Its Associated Factors: Kersa \\ District, Jimma Zone, Oromia Region, Ethiopia. Economics. Vol. 10, No. 2, 2021, pp. 40-45. doi: 10.11648/j.eco.20211002.11
}

Received: March 10, 2021; Accepted: June 2, 2021; Published: June 10, 2021

\begin{abstract}
Multipurpose cooperatives are often seen as key institutional intervention in enhancing farmers' access to markets, as one form of institution that fulfill exchange and co-ordination functions in an economy. This study Presented multipurpose cooperatives member participation in agricultural input marketing and associated factors at kersa woreda, Oromia Regional State, Ethiopia. Two-stage sampling procedures were used in this study. Primary data were collected through key informant interview, focus group discussions and personal observations while secondary data were collected through review of related literatures and different reports. Binary logit model was used to analyze quantitative data. Twelve independent variables were hypothesized and five of them positively influencing agricultural input marketing of multipurpose cooperative member's participation. The result showed that $66.36 \%$ of cooperative members were participants in agricultural input marketing where as 33.64\% were non-participants. The binary logit model result showed that age, education, landholding, change in standard of living due to joining of cooperative, membership in other cooperatives other than Multipurpose Cooperatives has influence agricultural input marketing of multipurpose cooperative member positively and significantly while the other two variables determined negatively and significantly. In conclusion, multipurpose cooperative members who are nearer to their office tend to more participate in marketing activity of agricultural input marketing than those who are far from their office. Therefore, the government has to facilitate road accessibility and District Cooperative promotion Agency has to give attention to address and support those who have no proximity to their office.
\end{abstract}

Keywords: Multipurpose Cooperative, Input Marketing, Participation, Ethiopia

\section{Introduction}

Co-operation as a way of life has been a tradition in finding the solution to the socio-economic problems of the people in the world in providing market access, credit, and information to producers [7]. Agricultural cooperatives were an integral part of the Ethiopian Growth and Transformation Plan I (GTP I) (2011-2015) and high priority to play a crucial role in strengthening the commercialization of smallholder agriculture in the second Growth and Transformation Plan II (GTP II) [3]. The multipurpose cooperative was one of the agricultural cooperatives that enable economically weak farmers and increase their collective bargaining power and individual capacities of Ethiopia and Sub-Sahara African countries [11]. Many
Ethiopian primary multipurpose cooperatives participate in the marketing of agricultural inputs and are involved in domestic marketing activities, financial transactions, and social capital development. They provide input services, create market opportunities, and help sell their members' products. They can allow for the exploitation of economies of scale and economies of scope, both by increasing the size of production and therefore, reducing unitary costs and by addressing output commercialization and input purchases simultaneously [12].

Moreover, the Ethiopian government places importance on promoting cooperatives as one of the main organizational mechanisms to enable the farmer to take inputs, credit, yield markets and to improve coordination within the smallholder sector [11]. The agricultural marketing policy of the country 
focuses on increasing the volume and quality of products for both domestic and export markets and an affordable market mechanism in which all actors can benefit. However, smallholder farmers face difficulty participating even in local markets due to subsistence production and inability to penetrate other influencing factors in searching for markets [5].

As a result, the Ethiopian government has developed a strategy for the cooperative societies and other market actors on agricultural marketing, making value chains more efficient is to reduce transaction costs and risks. Recently, the ATA has strongly asserted multipurpose cooperatives as preferential institutions for moving smallholders out of subsistence agriculture and linking them to emerging input and output markets [11].

However, the factors affecting multipurpose member's participation in agricultural input marketing, concerning shifting government policies and changing market conditions, have not been painted. Furthermore, MPC member farmers face difficulty in local markets due to subsistence production and the inability to penetrate other influencing factors searching for the market [7]. Hence, this study intends to examine member participation in agricultural input marketing and its associated factors in Kersa District, Jimma Zone, Oromia region, Ethiopia.

\section{Methodology}

\subsection{Description of the Study Area}

The study was conducted in Southwestern Ethiopia, Oromia region, Kersa district of Jimma Zone. Kersa district is located $325 \mathrm{~km}$ southwest of Addis Ababa. The district has a total of 32 kebeles, including 30 rural and two which are part of the capital town of the district called Serbo. The total population of the Kersa district is estimated at 178,647 . About 88,252 $(49.4 \%)$ are males and 90,395 (50.6\%) are females [9]. The study area is classified into two different agro-ecologies: midland and highland. About $90 \%$ of the study area falls into midland while the remaining $10 \%$ is highland. The climatic condition of the area is very favorable for agricultural activities in general and dairy production in particular. The area receives an annual rainfall of about 2000-2400 mm; the mean temperature is $13-26^{\circ} \mathrm{C}$ and the altitude ranges $1750-2200 \mathrm{~m}$ above sea level [9]. Agriculture is the most crucial source of household income in the study area. The area is mostly known for its vegetation coverage, suitability for coffee, crop, livestock, and bee production. Three major types of primary Cooperatives were found in the District. These are MPCs, saving and credit cooperatives, and other service cooperatives with 34,823 members of which 4,184 of them are women members. There are 30 multipurpose agricultural cooperatives in the District. The farming calendar of the districts is from June to August and like most parts of the country rain-fed agriculture is practiced. According to the same source, the living styles of the people in the area are characterized by mixed-farming and petty trades. The farmers' rear different livestock such as cattle, sheep, and goats basically to generate additional income to supplement the income generated from agricultural produce.

\subsection{Sampling Techniques}

According to Cooperative promotion office report of 2019 shows 30 MPCs were found in the District. For this study a two-stage sampling technique was used to the study area. First, out of 30 Multipurpose Cooperatives in the District, four of them were selected using simple random sampling since there are equal number multipurpose cooperatives in all kebeles and they are uniformly distributed.

In the 2nd stage, 196 sample respondents of Multi-Purpose Cooperatives members were selected using systematic random sampling from a list all sampled MPC from 5111 members based on simplified formula for proportions suggested by Yamane [13] as:

$$
\begin{aligned}
& n=\frac{N}{1+N(e)^{2}} \\
& n=\frac{5111}{1+5111\left(0.07^{2}\right)} \\
& n=196
\end{aligned}
$$

Where $\mathrm{n}$ is the sample size, $\mathrm{N}$ is the population size (Multipurpose cooperative members) and $\mathrm{e}$ is the level of precision where $\mathrm{e}=1$ - precision and assumed as $\mathrm{e}=7 \%$. Totally 196 respondents would be selected randomly from four multipurpose cooperatives based on probability proportional to size of cooperatives (Table 1)

Table 1. Sampling Procedure.

\begin{tabular}{llllllll}
\hline Name of the & Name of & \multicolumn{3}{l}{ Total member of MPCs } & \multicolumn{3}{l}{ Sampling size } \\
\cline { 3 - 8 } district & MPCOs & Male & Female & Total & M & F & Total \\
\hline Kersa & T/karsu & 1111 & 128 & 1239 & 43 & 5 & 48 \\
Kersa & A/Sabu & 1280 & 218 & 1498 & 48 & 9 & 57 \\
Kersa & Siba & 995 & 88 & 1083 & 37 & 7 & 42 \\
Kersa & Kitimbile & 1097 & 194 & 1291 & 41 & 8 & 49 \\
& Total & 448 & & 5111 & 167 & 29 & 196 \\
\hline
\end{tabular}

Source: Own survey, 2019

\subsection{Methods of Data Collection}

In order to capture relevant information both primary and secondary data were used for this study. Primary data were mainly collected from sample respondents, key informant interviews and focus group discussions. The primary data related to socioeconomic, institutional and demography of multipurpose cooperative members' participation in agricultural input marketing was collected through structured questionnaire. Secondary sources were from published and unpublished documents and reports were gathered to supplement primary data from relevant organizations. Moreover, discussions with district experts of the cooperatives promotion Agency offices and cooperative executive committee members were conducted.

A structured questionnaire was developed to collect the data from multipurpose cooperative members household. In addition to the questionnaire survey, four focus group 
discussions were held on different topics involving 6-8 participants. Key informant interviews were also conducted at each location with kebele management units, cooperative promotion experts, Development agent and cooperative committees' member using key informant interview checklists. Appropriately, the data collected at different levels was cross checked with field observations and other data sources.

\subsection{Method of Data Analysis}

The data was analyzed using Statistical Package for Social Sciences (SPSS) software version 20. An independent sample t-test and Chi-square test were used to see the presence of statistically significance difference and the association between those who participate and do not in terms of the hypothesized variables. Descriptive statistical analysis was used to discuss the results of the survey using frequency, mean, standard deviation and percentages. In addition, mean comparisons of independent samples and relation of sample category with variables of interest was explored. Binary logit econometric model was employed to know the influence of demographic, socioeconomic and institutional variables of members' participation decision in multipurpose cooperative in the study area.

\subsection{Model Specification}

The dependent variable of this study is MPC members' participation in agricultural input marketing and it is treated as a dummy variable which takes the value of one, if the multipurpose cooperative member is participant in agricultural output marketing, and zero otherwise. In this study, households who were considered as participant are those who are legally registered as members of MPCs and sell their agricultural output based on cooperative principle and their common interest. But, nonparticipants were MPC members who do not sell their agricultural output or product to their Cooperative.

The dependent variable: The dependent variable in this study is participation of multipurpose cooperative members in the agricultural input marketing. Participation is standard to measure the decision of member participation in agricultural output marketing.

Table 2. Summary of hypothesized variables.

\begin{tabular}{lll}
\hline Variables & Definitions & Type of Variables \\
\hline AGEHH & Age of HH members & Continuous \\
EDUCTN & Education level of HH & Continuous \\
FAMSIZE & Family size of HH & Continuous \\
LANDHOLD & Land owned by HH & Continuous \\
TLSH & Total livestock hold & Continuous \\
SHAREHOLD & Share holding & Continuous \\
NONFARMI & Non-farm income of HH & Continuous \\
EXPHHM & Expenditure of HH members & Continuous \\
DISTANCE & Distance of HH from MPC office & Continuous \\
OUTPUTP & Perception on output price & Dummy \\
CHSTDUCO & Perception on change in standard of living due to joining MPC & Dummy \\
MOTHRCOOP & Membership in other MPC & - \\
\hline
\end{tabular}

\section{Results and Discussions}

\subsection{Demographic Characteristics of the Sampled Respondents}

The total sample household members were 196 out of these sample households' distribution by sex constitutes $85.2 \%$ males headed and the rest $(14.8 \%)$ respondents are female headed. Out of the total interviewed sampled respondents' majorities $(95.96 \%)$ of them were married, the rest less than one percent respondents were single.

Table 3. Marital status and sex composition Of the sample respondent.

\begin{tabular}{llllll}
\hline Marital Status & Frequency & Percent & Sex & Frequency & Percent \\
\hline Single & 8 & 0.041 & Male & 167 & 85.20 \\
Married & 188 & 95.96 & Female & 29 & 14.80 \\
Total & 196 & 100 & & 196 & 100 \\
\hline
\end{tabular}

Source: Survey result 2019

\subsection{Results of Econometric Model}

The agricultural input marketing of multipurpose cooperative was determined by demographic, socioeconomic and institutional factors. In this section, selected explanatory variables were used to estimate the binary logistic regression model to analyze the factors affecting of MPC member participation decision in agricultural input marketing of multipurpose cooperatives to estimate the effects of the hypothesized explanatory variables on the probabilities of being participant or not participant in multipurpose cooperatives. It is appropriate to look into the problem of multicollinearity finding among the continuous variables and verify the degree of association among the hypothesized qualitative explanatory variables. It is relatively essential to ignore the variable with the VIF value exceeds 10 (this will happen if $R i^{2}$ exceeds 0.90 i.e. highly correlated) of the continuous variables. The values of contingency ranges between 0 and 0.75 with zero indicating no association between the variables and values close to 1 indicating high degree of association contingency coefficient computed for dummy variables.

These variables were selected on the basis of theoretical explanations, personal observations, association among the explanatory variables and the results of the survey studies, 
the 12 potential explanatory variables were entered into Logit analysis to determine the best subset of explanatory variables that are good predictors of the dependent variable. Estimates of the parameters of the variables expected to determine the participation decision are displayed on the Table 4 .

Table 4. Sign of explanatory variables used in binary Logit method.

\begin{tabular}{llllll}
\hline Explanatory Variables & B & S.E. & Wald & Sig. & Exp(B) \\
\hline AGE & .110 & .046 & 5.703 & $.017^{* *}$ & 1.116 \\
EDULM & .705 & .207 & 11.564 & $.001^{* * *}$ & 2.025 \\
FAMSIZE & .299 & .226 & 1.751 & .186 & 1.348 \\
LANDHOLD & 1.844 & 1.024 & 3.243 & $.072^{*}$ & 6.323 \\
TLSH & -.880 & .274 & 10.304 & $.001^{* * *}$ & .415 \\
SHAREHOLD & -.181 & .423 & .184 & .668 & .834 \\
NONFARMI & .000 & .000 & .376 & .540 & 1.000 \\
EXPHHM & .000 & .000 & 1.012 & .314 & 1.000 \\
DISTANCE & -.892 & .368 & 5.871 & $.015^{* *}$ & .410 \\
OUTPUTP & 1.077 & .974 & 1.223 & .269 & 2.935 \\
CHSTDUCO & 3.711 & 1.096 & 11.466 & $.001^{* * *}$ & 40.887 \\
MOTHRCOP & 2.199 & 1.144 & 3.697 & $.055^{*}$ & 9.015 \\
Constant & -.168 & 3.002 & .003 & .955 & .846 \\
$X^{2}$ (Chi-square) value & & & 197.950 & \\
-2 Log likelihood & & & 52.477 & & \\
Correctly predicted over all sample \% & 95.9 & & \\
Correctly predicted participant \% & & 96.2 & & \\
Correctly predicted non-participant \% & 95.5 & & \\
\hline
\end{tabular}

$*, * *, * *$ Significant at less than 10,5 , and $1 \%$ level of significance

The logit model results used to study factors influencing the MPC member participation in agricultural output marketing are shown in table 4 . The various goodness of fit measures state that the model fits that data well. The maximum likelihood estimates of the logistic regression models are significant at less than $1 \%$ probability of participation. The models percent correctly predicted 95.9, correctly predicted participant 96.2 and correctly predicted non-participant 95.5. This indicates the existences of useful information in the estimated models. Another measure of goodness of fit is based on a method that classifies the predicted value of the dependent variable, participation of MPC members in agricultural input marketing, as 1 if participant and 0 otherwise.

This classification is the result of cross-classifying the outcome variable, $y$, with a dichotomous variable whose values are derived from the estimated logistic probabilities. In this approach; estimated probabilities are used to predict group membership. They say that, if the model predicts group membership accurately according to some criteria, then this is thought to provide evidence that the model fits. The model explained about $95.9 \%$ of the total variation in the sample for participation of agricultural output marketing. Correctly predicted figures for participants were about 96.2\%; while correctly predicted sample size for nonparticipants were $95.5 \%$. Among the 14 variables used in the model, 9 variables were significant with respect to participation of agricultural input marketing. The effect of the significant explanatory variables on participation in study area is discussed below:
Age of $\mathrm{HH}$ head: Age of $\mathrm{HH}$ was positively and significantly influencing the probability of MPC members' participation in agricultural input marketing at 5 Percent. This implies that as the age of MPC members' increases by one year the probability of their participation in agricultural input marketing increases and this is possible because as cooperative member gets more and more experience in their agricultural output marketing, business skill, accumulate wealth and use better planning than the younger ones, the behavior farmers averting risk increases with increasing in age and experiences of the household head. Hence, they may prefer to participate in the agricultural input marketing. This finding was in line with Mahmud's study [8] while in contrast with Alema and Muthyalu's study $[2,10]$.

Educational level of members (EDULM): As hypothesized, education level was positively and significantly associated with participation in input marketing at less than $1 \%$ probability level. The education level of members is significant at $1 \%(p=0.001)$ level. This implies as the years of formal education cooperative members attended increases, it influences their participations in agricultural input marketing positively. Educated cooperative member can have more access, knowhow and understand the benefits of making transactions with the cooperatives. The odds ratio for the variable implies that other variables constant increase in education level of MPCs member by a year leads to increase the probability of agricultural output marketing MPC member participation by a factor of 2.025 . This implies more educated farmers were tending to participate more as result of awareness they have in making transaction with cooperatives. The result is inconformity with Addisu's study [1].

Land Hold of HH: It was found that land hold had positively and significantly influenced the probability of participation of agricultural input marketing at less than $10 \%$ significant level. This result implies that farmers with large handhold are more likely to participate in agricultural input marketing than those farmer members who have small land size. The odds ratio of 6.323 for land hold indicates that, other things being constant, the odds ratio in favor of participation in agricultural input marketing increases by a factor of 6.323 as the land hold increases by one hectare. This result shows that households with larger land size produce more and likely participate in agricultural input marketing. This finding agrees with findings of Daniel's study [4].

Livestock holding: The total livestock holding of MPC members was negatively significant at less than 1 percent level of significance. This shows that, as household livestock increases by one TLU, the probability of participating in agricultural input marketing decreases by a factor of -0.88 .

Distance of MPC:-It is the distance of multipurpose cooperatives office from their house residence that has influence on the probability of participation of farmer members in the agricultural input marketing. The logit model estimates indicated that this variable is negatively and significantly related to member participation in input and 
output marketing at less than 5\% probability level. This result may be due to the fact that members, who live relatively nearer to MPCs office, have more chance to participate in marketing. This could be due to the fact that it is more convenient to extension services and cooperative promoters in giving training and support than distant households. Furthermore, the cooperative promoting agents focus in helping in creation of awareness may be concentrated on the nearest members to extensions office because currently one cooperative promoter has responsibility of three villages. The odds ratio revealed that as distance increases by a $\mathrm{Km}$, member participation in agricultural input marketing decreases by 0.410 and this study result coincides with Muthyalu and Mahmud's study [10,8].

Change on standard of living due to joining to cooperative (CHSTDUCO): This is a dummy explanatory variable coded as 1 if the standard of living due to joining a cooperative (became a cooperative membership) of MPCs member has changed or otherwise 0 . Change on standard of living due to joining MPCs is Positive and significant at less than one percent participation level. The odds ratio reveals that change in the standard of living of MPC member increases the probability of agricultural input marketing by 40.887 . This finding is similar to Alema's study [2].

Membership in other cooperatives (MOTHCOP): Membership in other cooperatives i.e. other than the multipurpose cooperatives has positive and significance influence at less than $10 \%$ the probability of participation in the agricultural input marketing. The odds ratio in favor of participation in agricultural input marketing increases by a factor of 9.015 as the membership of farmer members in other cooperative become increases by one cooperative. This this result was in line with Muthyalu and Alema's study [10, 2].

In general, the participation of multipurpose cooperatives in the agricultural input marketing by their members was significantly influenced by age, education, land hold, Total livestock hold, distance of the cooperative office from the household house, change in standard of living due to joining cooperative and membership in other cooperatives. However, out of the 9 significant explanatory variables two of them (land hold and Membership in other cooperative than MPC) were influenced the participation of cooperative members in the agricultural input marketing by cooperatives significantly at $10 \%$, four of them at $5 \%, 3$ of them at $1 \%$ probability level respectively.

\section{Conclusion and Recommendation}

This study analyzed determinants of MPCs members' participation in agricultural input marketing. The descriptive statistics and econometric model were also used for analyzing the data. T-test was used to compare the mean values of the continuous explanatory variables and examine the existence of statistically significant differences between participants and non-participants of MPCs members in agricultural output marketing. The T-test showed significant difference in the age, educational level of members, total live stocks hold, land hold and distance of $\mathrm{HH}$ members from MPCs office. Discrete variables were also compared using Chi-square test to see if there is statistically significant difference between the two groups. The Chi-square test also revealed that the discrete variables: Change in standard of living due to joining cooperative, membership in other cooperative Other than MPCs, are found to influence members decision in agricultural output marketing activity at the different levels of significance. The result of binary Model shows that age, educational level of members, total livestock hold, distance, change in standard of living due to joining cooperative, membership in other cooperative than MPCs, are found to influence MPCs members' decision in input marketing activity at the different levels of significance. However, family size, share hold, on-farm income, expenditure in inputs, and output price perception were not affecting their participation.

The study revealed that distance of MPC members from their office and total livestock hold has negative and significant influence on probability of participating in agricultural input marketing. MPC members nearer to their office tend to more participate in marketing activity of agricultural input marketing than those who are far from their office. Therefore, the government has to facilitate road accessibility and District Cooperative promotion Agency has to give attention to address and support those who have no proximity to their office.

\section{References}

[1] Addisu, W., 2011. The Role of Multipurpose Farmer Cooperatives in the Supply Chain of Wheat in Gedeb-Hasasa Woreda, Oromia Regional State, Ethiopia (Doctoral dissertation, Mekelle University).

[2] Alema, W. A., 2008. Analysis of the Role of Cooperatives in Agricultural Input and Output Marketing in Southern Zone of Tigray, Ethiopia (Doctoral dissertation, Mekelle University).

[3] COMMISSION, 2015. The Second Growth and Transformation Plan (GTP II) (2015/16-2019/20) (Draft), Addis Ababa: The Federal Democratic Republic of Ethiopia.

[4] Daniel, B., 2006. Performance of primary agricultural cooperatives societies and determinants of members' decision to use as a marketing agent: Adaa Liben and Lume Districts.

[5] Ephrem, D., 2014. Assessment of Members Perceptions towards Factors Influencing the Success of Cooperatives: A survey of Agricultural Marketing Cooperatives in Becho Woreda (Doctoral dissertation, Mekelle University).

[6] FCA, 2016. Asummarized Data on Cooperatives as of January, 1 2016, www.fca.gov.et/webapp/php/documents/Saturday\%202nd\%20 of\%20July\%202016\%2009_07_24\% 20PM\%20Document_88.p $\overline{d f}$.

[7] Francesconi, G. N. and Heerink, N., 2011. Ethiopian agricultural cooperatives in an era of global commodity exchange: does organisational form matter? Journal of African Economies, 20 (1), pp. 153-177. 
[8] Mahmud, J., 2008. Analysis of the role of cooperatives in agricultural input output marketing in Eastern Zone, Tigray Region (Doctoral dissertation, Mekelle University).

[9] Kersa Agriculture and Natural Resource District Office., 2019.

[10] Muthyalu, M., 2013. The factors that influence the participation of co-operative members in the agricultural input and output marketing: a case study of Adwa district, Ethiopia. Journal of Business Management and Social Sciences Research, 2 (4).
[11] Navarra, C., Borzaga, C. and Franchini, B., 2017. Identifying processes and policies conducive to cooperative development in Africa. An exploratory study on cooperative development projects in the agricultural sector. Summary, concluding remarks and hypotheses for further work (No. 14, p. 17). Euricse research report.

[12] Thompson, S., 2015. Towards a social theory of the firm: worker cooperatives reconsidered. Journal of Co-operative Organization and Management, 3 (1), pp. 3-13.

[13] Yamane, T., 1967. Elementary sampling theory. Englewood Cliffs, N. J., Prentice-Hall. 